\title{
Glucocorticoids, state-dependent reproductive investment and success in the face of danger in a long-lived bird
}

\author{
Kristina Noreikiené ${ }^{1}\left[\right.$ Cim Jaatinen ${ }^{2} \cdot$ Benjamin B. Steele $^{3} \cdot$ Markus Öst $^{4,5}$
}

Received: 30 April 2020 / Revised: 10 November 2020 / Accepted: 24 November 2020 / Published online: 14 December 2020

(c) The Author(s) 2020

\begin{abstract}
Glucocorticoid hormones may mediate trade-offs between current and future reproduction. However, understanding their role is complicated by predation risk, which simultaneously affects the value of the current reproductive investment and elevates glucocorticoid levels. Here, we shed light on these issues in long-lived female Eiders (Somateria mollissima) by investigating how current reproductive investment (clutch size) and hatching success relate to faecal glucocorticoid metabolite [fGCM] level and residual reproductive value (minimum years of breeding experience, body condition, relative telomere length) under spatially variable predation risk. Our results showed a positive relationship between colony-specific predation risk and mean colony-specific fGCM levels. Clutch size and female fGCM were negatively correlated only under high nest predation and in females in good body condition, previously shown to have a longer life expectancy. We also found that younger females with longer telomeres had smaller clutches. The drop in hatching success with increasing fGCM levels was least pronounced under high nest predation risk, suggesting that elevated fGCM levels may allow females to ensure some reproductive success under such conditions. Hatching success was positively associated with female body condition, with relative telomere length, particularly in younger females, and with female minimum age, particularly under low predation risk, showing the utility of these metrics as indicators of individual quality. In line with a trade-off between current and future reproduction, our results show that high potential for future breeding prospects and increased predation risk shift the balance toward investment in future reproduction, with glucocorticoids playing a role in the resolution of this trade-off.
\end{abstract}

Keywords Corticosterone $\cdot$ Cost of reproduction $\cdot$ Eider $\cdot$ Individual quality $\cdot$ Predation $\cdot$ Residual reproductive value

Communicated by L. Fusani.

Supplementary Information The online version contains supplementary material available at https://doi.org/10.1007/s1033 6-020-01847-9.

Kristina Noreikienè

kriste.noreikiene@gmail.com

$\triangle$ Markus Öst

markus.ost@abo.fi

1 Chair of Aquaculture, Institute of Veterinary Medicine and Animal Sciences, Estonian University of Life Sciences, Kreutzwaldi tn. 46, Tartu, Estonia

2 Nature and Game Management Trust Finland, Degerby, Finland

3 Department of Natural Sciences, Colby-Sawyer College, New London, NH, USA

4 Environmental and Marine Biology, Åbo Akademi University, Artillerigatan 6, 20520 Turku, Finland

5 Novia University of Applied Sciences, Raseborgsvägen 9, 10600 Ekenäs, Finland 


\section{Zusammenfassung}

Glukokortikoide, zustandsabhängige Reproduktionsinvestition und -erfolge bei Gefahr bei einer langlebigen Vogelart Glukokortikoid-Hormone können Trade-offs zwischen der gegenwärtigen und zukünftigen Reproduktion vermitteln. Das Verstehen ihrer Rolle wird jedoch durch das Prädationsrisiko erschwert, dass gleichzeitig den Wert der gegenwärtigen Reproduktionsinvestition beeinflusst und den Glukokortikoidspiegel erhöht. Hier klären wir diese Fragen bei Weibchen der langlebigen Eiderente (Somateria mollissima), indem wir untersuchten, wie die gegenwärtige Investition in die Reproduktion (Gelegegröße) und der Schlupferfolg mit dem Gehalt an fäkalen Glukokortikoid-Metaboliten (engl. faecal glucocorticoid metabolite, fGCM) und dem Restreproduktionswert (minimale Bruterfahrung, Körperkondition, relative Telomerlänge) unter räumlich variablem Prädationsrisiko zusammenhängen. Unsere Ergebnisse zeigten eine positive Beziehung zwischen dem koloniespezifischen Prädationsrisiko und dem mittleren koloniespezifischen fGCM-Spiegel. Die Gelegegröße und der fGCM-Spiegel der Weibchen waren nur bei starker Nestprädation und bei Weibchen mit guter Körperkondition, die nachweislich eine längere Lebenserwartung hatten, negativ korreliert. Weiterhin fanden wir heraus, dass jüngere Weibchen mit längeren Telomeren kleinere Gelege hatten. Der Abfall im Schlupferfolg mit zunehmendem fGCM-Spiegel war bei hohem Nestprädationsrisiko am wenigsten ausgeprägt, was darauf hindeutet, dass erhöhte fGCM-Spiegel den Weibchen unter solchen Bedingungen einen gewissen Reproduktionserfolg sichern können. Der Schlupferfolg war positiv mit der Körperkondition der Weibchen, der relativen Telomerlänge (insbesondere bei jüngeren Weibchen) und dem Mindestalter der Weibchen (insbesondere bei schwachem Prädationsrisiko) assoziiert, was den Nutzen dieser Messgrößen als Indikatoren für die individuelle Qualität zeigte. In Übereinstimmung mit dem Trade-off zwischen gegenwärtiger und zukünftiger Reproduktion zeigen unsere Ergebnisse, dass ein hohes Potenzial für zukünftige Brutmöglichkeiten und ein verstärktes Prädationsrisiko das Gleichgewicht zugunsten von Investition in die zukünftige Reproduktion verschieben, wobei Glukokortikoide bei der Lösung dieses Trade-offs eine Rolle spielen.

\section{Introduction}

The 'cost of reproduction' hypothesis (Williams 1966) assumes a trade-off between current reproductive investment (CRI) and residual reproductive value (RRV) (Stearns 1992; Clark 1994). In iteroparous animals, RRV is expected to be higher while CRI is expected to be lower in young individuals, as future reproductive opportunities decrease late in life (Velando et al. 2006). However, the relative value of CRI and RRV is also affected by extrinsic factors such as predation which shapes current reproductive success (Ghalambor and Martin 2000). Reduced reproductive effort under high predation risk may save resources for reproduction during safer periods and thus increase lifetime reproductive success. For example, in an elaborate experimental study eliminating direct predation but using playbacks of predator calls, perceived predation risk alone significantly reduced both clutch size and chick survival in songbirds (Zanette et al. 2011).

Considerable interest has been given to glucocorticoid hormones as candidate physiological mediators of the tradeoff between CRI and RRV. For example, bird species with a higher value of the current brood relative to RRV mount weaker corticosterone responses to stressors, suggesting a putative role of glucocorticoids in mediating the cost of reproduction (Bokony et al. 2009). Besides their important role in regulating energy expenditure (Jimeno et al. 2018), glucocorticoids are also secreted upon exposure to the presence or cues of predators (Cockrem and Silverin 2002; Ibáñez-Álamo et al. 2011). The resulting elevated glucocorticoid levels should favour self-maintenance and survival processes at the expense of less immediately vital functions such as reproduction (Wingfield et al. 1998). Thus, recurring predator stimuli may lead to chronically elevated glucocorticoid levels (Monaghan 2014) and result in lower breeding propensity (Öst et al. 2018), increased nest desertion (Thierry et al. 2013) and, ultimately, reduced fitness (Bonier et al. 2009b). Nevertheless, the relationship between baseline glucocorticoid levels and fitness is closely dependent on context (Bonier et al. 2009a; Jaatinen et al. 2013). For example, moderate increases in glucocorticoids may positively influence parental performance, by enhancing foraging effort before and during egg-laying (Crossin et al. 2012). Furthermore, glucocorticoids are simultaneously affected by predation risk and involved in the regulation of the trade-off between CRI and RRV. This dual role complicates interpretations on the role of glucocorticoids in mediating reproductive trade-offs under variable risk of predation.

Estimating an organism's potential for future reproduction can be difficult, complicating efforts to resolve the trade-off between current and future reproduction. Recent advancements in molecular ecology suggest that telomeres may serve as a potential proxy for RRV (Heidinger et al. 2012). These nucleoprotein structures found at the ends of chromosomes shorten with every cell division (Vaziri et al. 1994) and in response to physiological (Hau et al. 2015) or reproductive stress (Heidinger et al. 2012). Telomeres are increasingly regarded as suitable proxies for biological state (Mizutani et al. 2013; Hau et al. 2015; Angelier et al. 2019), where individuals in a poor biological state face reduced life expectancy. Consequently, there tends 
to be a positive correlation between telomere length and survival (e.g., Heidinger et al. 2012), likely resulting in higher RRV. Although increased reproductive effort may accelerate telomere shortening (e.g., Sudyka et al. 2014), this relationship is far from universal (Beaulieu et al. 2011; Plot et al. 2012; Bauch et al. 2013), suggesting that some individuals may be able to allocate more resources to maintaining both telomeres and reproductive effort (Cerchiara et al. 2017).

Here, we investigate the trade-off between CRI and RRV under varying colony-specific predation risk and for individually variable faecal glucocorticoid metabolite [fGCM] levels. Elevated baseline GCs could promote the re-allocation of resources from reproduction to survival when the value of CRI is expected to be lower (e.g. Wingfield et al. 1998), such as under high predation risk. First, we tested the assumption that higher predation risk is associated with elevated baseline fGCM levels. Drawing on the cost of reproduction hypothesis assuming a trade-off between CRI and RRV, we predicted that (1) individuals exposed to higher predation risk will decrease their CRI, (2) this effect is pronounced in individuals with higher RRV (Clark 1994) and that (3) adjustment of initial reproductive investment to prevailing predation risk will positively influence reproductive success. Finally, we assessed the validity of female body condition, telomere length and breeding experience as individual quality attributes, expecting positive associations with hatching success (Clutton-Brock 1988).

To this end, we studied long-lived female Eider ducks (Somateria mollissima) breeding in the northern Baltic Sea, in a study population subject to intense predation pressure on adults, eggs and ducklings (Öst et al. 2018). We used clutch size as a proxy for CRI, because Eiders mainly utilize stored reserves to produce the yolk (Hobson et al. 2015) and because larger clutches are more costly to care for (Hanssen et al. 2005; Neggazi et al. 2016). As proxies for RRV, we used female minimum breeding experience (in years), body condition at hatching and relative telomere length. The body condition of first-time breeders in Eiders has been found to be positively related to their subsequent survival (Ekroos et al. 2012) and female body condition is positively correlated with reproductive success (Lehikoinen et al. 2010). Furthermore, female body condition exhibits limited plasticity between seasons (Jaatinen and Öst 2011; Ekroos et al. 2012). Thus, body condition should be regarded as a suitable proxy for RRV. Telomere length may represent a complimentary measure of RRV. Thus, although the telomere length of adult female Eiders is not significantly associated with age or body condition, reproductive success may be achieved at the expense of telomere length (Noreikiene et al. 2017). Female reproductive success was measured as proportional hatching success. Faecal glucocorticoid metabolite [fGCM] levels provided an integrated measure of adrenocortical activity over hours to days (Nilsson et al. 2008; Legagneux et al. 2011).

\section{Materials and methods}

\section{Study area and species}

This study was conducted in 2011 at Tvärminne Zoological Station, western Gulf of Finland $\left(59^{\circ} 50^{\prime} \mathrm{N}, 23^{\circ} 15^{\prime} \mathrm{E}\right)$. A map of the study area can be found in Waldeck et al. (2008). Eiders breed on the majority of islands in this archipelago, comprising both forested and non-forested islands. Eiders arrive at the breeding grounds at the end of March-first half of April and egg-laying typically occurs at the end of Aprilfirst half of May (Lehikoinen et al. 2006). Re-nesting after failed breeding attempts is extremely rare (Öst et al. 2018). Females take regular recesses from incubation, mainly to drink, as fatty acid profiling of incubating females suggests that feeding during incubation is uncommon (Hellman 2017).

\section{Female trapping and sampling}

Nesting Eider females $(N=197)$ were captured with hand nets on 20 different islands (mean $\pm \mathrm{SD}=9.9 \pm 11.7$ individuals per island), weighed to the nearest $10 \mathrm{~g}$, measured for structural size (radius-ulna length to the nearest $1 \mathrm{~mm}$ ), and ringed with a standard metal ring. Trapping was timed to roughly coincide with the latter part of the incubation period because the risk of human-induced nest desertion is significantly lower if Eider nests are visited during the later phases of incubation (Bolduc and Guillemette 2003). Because females are not ringed as ducklings, we used a relative age indicator which estimates (minimum) years of breeding experience (mean $\pm \mathrm{SD}=2.6 \pm 3.68$ years; range $[0-16]$ ), given by the number of years since first capture (Öst and Steele 2010). This variable approximates female age (Jaatinen and Öst 2011) since females exhibit strong breeding philopatry (Öst et al. 2011) and therefore previously unringed females are younger than those already ringed. The majority of breeding females are trapped annually (2011: 61.3\%), with a constant trapping effort for the past decades (Jaatinen and Öst 2011). Nevertheless, we acknowledge a lack of precision in the variable, because it scores all unringed females as inexperienced, and ignores variation in the age at first breeding (typically 3 years, range $2-5$ years; Hario and Rintala 2009). Nevertheless, this imprecision renders the current analysis conservative in its ability to detect effects related to female age.

Female blood samples $(<1 \mathrm{ml})$ were extracted from a brachial vein. When alarmed, incubating female Eiders readily spray faeces on their eggs that deter predators. Faecal 
samples were immediately collected from the female or from the nest cup and placed into Whirl-Pak (Nasco) bags. Concentrations of fGCM were unaffected by our handling since all samples were collected before any capture-induced increases in fGCM levels are detectable (6-10 min after capture in geese, Legagneux et al. 2011). Blood and faecal samples were immediately stored on ice and transferred to $-20{ }^{\circ} \mathrm{C}$ within $4 \mathrm{~h}$ of sampling.

\section{Reproductive investment and female body condition}

Mean clutch size was 4.5 eggs (range 2-7). Conspecific brood parasitism is rare (ca 6\% of eggs; Waldeck et al. 2004). We used egg flotation (Kilpi and Lindström 1997) to determine the incubation stage (mean $\pm \mathrm{SD}=16.49 \pm 4.50$ days of incubation), laying and hatching dates. The estimated and true incubation stages do not statistically differ from each other (Kilpi and Lindström 1997). Female body condition indices were determined if eggs had been incubated for at least 8 days (egg-laying may otherwise still be in progress; Öst et al. 2008). This index was given by the standardized residuals of a regression of log-transformed projected weight at hatching (response variable) on log-transformed radiusulna length (Öst and Steele 2010). Projected weight at hatching was obtained by subtracting an estimate of the expected body weight loss during the remaining incubation time from measured incubation body weight at capture. Because females abstain from feeding during incubation and incubation stage at capture is variable, we derived an estimate of mean weight loss rate during incubation as the slope of the regression of log-transformed body mass (response variable) on log-transformed incubation time and projected hatching date (Öst et al. 2008).

\section{Hatching success}

Hatching success was determined during a nest revisit at the expected hatching date based on egg flotation. Successful nests contained either live ducklings or eggshells with intact membranes (Öst and Steele 2010). Such eggshell remnants are clearly distinct from those associated with nest depredation; in the latter case eggshells are shattered and inner egg membranes are bloody and attached to the eggshell fragments. Since hatching status was based on systematic daily nest monitoring, any signs of successful hatching or egg predation were fresh and not appreciably affected by exposure to weather conditions. If the brood had hatched and left prior to our arrival, leaving only intact egg membranes (indicating successful hatching) with no remains of depredated eggs, the viable clutch size was deemed the same as the clutch size recorded at female capture (Jaatinen et al. 2014). We recorded the number of successfully hatched eggs (hatched ducklings surviving to leave the nest) and unhatched eggs (eggs failing to hatch due to depredation, abandonment and occasionally inviability). We were able to unequivocally determine nest fate in 165 out of the 197 nests $(83.8 \%)$.

\section{Predation risk}

The two most important predators of adult female Eiders are the White-tailed Sea Eagle (Haliaeetus albicilla) and the American Mink (Neovison vison) (Öst et al. 2018). Clutches are depredated by Hooded Crows (Corvus corone cornix), Ravens (Corvus corax) and large gulls (Larus spp.) (Seltmann et al. 2014). We quantified colony-specific predation risk (mean $\pm \mathrm{SD}=0.17 \pm 0.11$; range [0-0.67]) by calculating the proportion of depredated nests at the first encounter of all nesting attempts on a given island (Öst et al. 2011). The total number of nesting attempts was the sum of actively incubated, early-depredated and abandoned nests, and nests that had already hatched when first found. Basing the predation index on the number of initial nest predation events was necessary for two reasons. First, this yielded an index unaffected by our nest monitoring that may induce additional nest depredation. Second, nests of incubating and blood-sampled females that were later found depredated (see "Hatching success" above) were not included in the count of early-depredated nests, which was used for calculating the colony-specific predation risk. Thus, we avoided statistical circularity otherwise arising due to an association between proportional hatching success (response variable) and colony-specific predation risk (independent variable). Our predation risk index is likely unbiased by variation in the timing of initial nest monitoring relative to island-specific nesting phenology. Thus, the time difference between the island-specific median date of nest visits and median estimated hatching dates (mean $\pm \mathrm{SD}=-12.19 \pm 3.35$ day s) was unrelated to colony-specific predation risk $(r=0.02$, $p=0.93, N=21)$. The predation index accurately captures colony-specific danger because there is a tight correlation $(r=0.75)$ between predation on incubating females and eggs (Öst et al. 2018), based on the same nest predation index as here.

Inclusion of proportional nest cover as a covariate was necessary to account for a potential increase in clutch size with increasing nest concealment, as (often undetected) partial clutch predation may disproportionately affect nests offering less protective covering (Öst et al. 2008). Female Eiders with different glucocorticoid profiles may also differ in their nest cover preferences (D'Alba et al. 2011; Seltmann et al. 2014). To quantify the structural cover of the nest, digital photographs were taken by placing an upwardfacing Olympus C-740 camera equipped with a $42-\mathrm{mm}$ Opteka semi-fisheye lens in the nest (Öst and Steele 2010). The software Image Tool 3.00 (University of Texas Health 
Science Center, San Antonio) was used to convert images to greyscale and the pixels were then converted to either black or white using a threshold so that sky was white and all rocks and vegetation were black (Öst et al. 2008). The proportion of black pixels was used as a quantitative measure of nest cover.

\section{Faecal glucocorticoid metabolites}

Faecal glucocorticoid metabolites (fGCM) were measured by radioimmunoassay (RIA) using a double-antibody kit (ImmuChemTM Double Antibody, Corticosterone, 1251 RIA Kit, MP Biomedicals, Orangeburg, NY). The RIA kit protocol for Eider fGCM measurements in this population is described by Jaatinen et al. (2013). The mean sensitivity of the fGCM assay was $10.6 \mathrm{ng} / \mathrm{g}$ and the mean $( \pm \mathrm{SD})$ fGCM concentration in the samples was $222.25 \mathrm{ng} / \mathrm{g}( \pm 136.77)$ (range 43.0-961.1 ng/ml, $\mathrm{N}=185$ ). The intra-assay $\mathrm{CV}$ was $5 \%$ and inter-assay CV was $12.29 \%$. As a biological validation of the assay, injections of a corticosterone-releasing hormone (adrenocorticotropic hormone, ACTH) induce increases in fGCM concentrations 1-4 h post-injection in two other waterfowl species (Nilsson et al. 2008; Legagneux et al. 2011). Although the determination of female fGCMs took place after clutch completion, this is not a critical limitation. First, female faeces start to accumulate immediately after incubation onset, typically occurring after the second egg is laid (e.g., Andersson and Waldeck 2006). Thus, fGCM concentrations are likely to provide an integrated measure of faecal hormone profiles accumulated over a period of several days. Second, fGCM levels do not systematically change with advancing incubation (Jaatinen et al. 2013).

\section{Telomere length}

We measured relative telomere length (TL) in female Eider blood using real-time quantitative PCR (qPCR; Cawthon 2002; Criscuolo et al. 2009). This method has been validated for use in ecological studies (Criscuolo et al. 2009; Heidinger et al. 2012), and optimized for use in Eiders (Noreikiene et al. 2017; Öst et al. 2020). We, therefore, provide a detailed account of the telomere qPCR as supplementary information (Supplementary file 1).

\section{Data analysis}

All analyses were conducted using the statistical software $\mathrm{R}$ 3.4.3 (R Development Core Team 2017). Because predation risk was assessed at the colony level, we tested the association between colony-specific predation risk and mean colony-specific fGCM level, after log-transforming individual fGCM values to meet the normality assumption required of Pearson correlation.
To analyse variation in clutch size, we constructed a linear mixed model including measures of RRV (minimum breeding experience in years, body condition, TL), colonyspecific predation risk, and female fGCM level. The initial model included the two-way interactions between fGCM and each RRV variable and between fGCM and predation risk, respectively. These interactions were selected because rather than expecting a simple, linear association between fGCM and the response variables (clutch size and hatching success), we should consider both RRV and predation risk as potential moderators between fGCM levels and our response variables (see "Introduction"). An additional interaction between minimum breeding experience and predation risk was added to control for possible age-associated changes in investment decisions under predation risk. Proportional nest cover was included as a covariate. Colony identity was included as a random effect to account for the non-independence of observations from the same colony. This random effect may potentially exhibit redundancy with the colony-level variable predation risk. Nevertheless, inclusion of colony identity was warranted because of its nonzero variance $($ variance $( \pm 95 \% \mathrm{CI})=0.175(0.021-1.47))$. Furthermore, a model without a random effect did not offer a better fit (likelihood-ratio test (LRT): $\chi^{2}{ }_{1}=0.21, p=0.64$ ), indicating the presence of variation among colonies not captured by the fixed effects.

To analyse variation in proportional hatching success, created by combining the number of viable and nonviable offspring using 'cbind' in R, we constructed a generalized linear mixed model with binomial error distribution (logit link function) and Laplace parameter estimation. The fixed effects were identical as in the clutch size model, except for the addition of timing of breeding, to control for a seasonal decrease in nest success (Jaatinen et al. 2013), and clutch size, to control for potential clutch-size dependent hatchability. Inclusion of colony identity controlled for pseudoreplication. Colony identity had a variance component exceeding zero [variance $( \pm 95 \% \mathrm{CI})=0.40(0.07-1.75)$ ], and its inclusion significantly improved model fit (LRT: $\left.\chi_{1}^{2}=11.69, p<0.001\right)$. Additionally, because the incubation stage at capture may influence nest desertion (Bolduc and Guillemette 2003), we tested whether the addition of incubation stage to the final model of proportional hatching success (containing only significant terms; see below) was necessary. Incubation stage at capture was not significant $(p=0.09)$, and the results remained quantitatively almost identical, with no loss or gain of significance for any term. We, therefore, excluded the incubation stage at capture from the final model presented here.

The significance of each fixed effect was assessed by comparing models with and without the term using likelihood ratio tests until only significant terms $(\alpha<0.05)$ remained (Tables 1,2). Backward stepwise elimination is 
Table 1 Final linear mixed model (in bold) and model selection for variables explaining clutch size in female Eiders, with colony identity included as a random effect
Table 2 Final generalized linear mixed model (in bold) and model selection for variables explaining the proportion of successfully hatched eggs ( $\mathrm{P}($ hatch $)$ ) in female Eiders, with colony identity included as a random effect

\begin{tabular}{|c|c|c|c|}
\hline Explanatory variable $^{\mathrm{a}}$ & Parameter estimate \pm SE & df & $t(p)^{\mathrm{a}}$ \\
\hline Breeding experience & $-0.094 \pm-0.057$ & 115 & $-1.636(0.105)$ \\
\hline TL & $-0.192 \pm 0.141$ & 115 & $-1.361(0.176)$ \\
\hline Body condition & $0.345 \pm 0.150$ & 115 & $2.299(0.023)$ \\
\hline Predation risk & $6.862 \pm 2.084$ & 17 & $3.293(0.004)$ \\
\hline fGCM, ng/g & $0.005 \pm 0.002$ & 115 & $2.846(0.005)$ \\
\hline Proportional nest cover & $0.762 \pm 0.372$ & 115 & $2.047(0.043)$ \\
\hline Breeding experience $\times$ TL & $0.074 \pm 0.037$ & 115 & $1.990(0.049)$ \\
\hline Body condition $\times$ fGCM & $-0.002 \pm 0.001$ & 115 & $-2.451(0.016)$ \\
\hline Predation risk $\times$ fGCM & $-0.037 \pm 0.01$ & 115 & $-3.844(<0.001)$ \\
\hline $\mathrm{TL} \times \mathrm{fGCM}$ & $-0.0015 \pm 0.001$ & 114 & $-1.326(0.188)$ \\
\hline Breeding experience $\times \mathrm{fGCM}$ & $-0.0003 \pm 0.00026$ & 113 & $-1.257(0.211)$ \\
\hline Breeding experience $\times$ body condition & $-0.0051 \pm 0.0234$ & 112 & $-0.22(0.826)$ \\
\hline Breeding experience $\times$ predation risk & $0.0129 \pm 0.256$ & 111 & $0.051(0.960)$ \\
\hline TL $\times$ body condition & $-0.0152 \pm 0.144$ & 110 & $-0.105(0.917)$ \\
\hline
\end{tabular}

fGCM faecal glucocorticoid metabolites, $S E$ standard error, $d f$ degrees of freedom, $T L$ telomere length ${ }^{\mathrm{a}} t$ statistics and significance of the term $(\alpha=0.05)$ were obtained by comparing models with and without the given term

\begin{tabular}{lcl}
\hline Explanatory variable $^{\mathrm{a}}$ & Parameter estimate $\pm \mathrm{SE}$ & $z(p)^{\mathrm{a}}$ \\
\hline Breeding experience & $\mathbf{0 . 4 8 7} \pm \mathbf{- 0 . 0 9 7}$ & $\mathbf{4 . 9 9 5}(<\mathbf{0 . 0 0 1})$ \\
Timing of breeding & $\mathbf{- 0 . 1 0 3} \pm \mathbf{0 . 0 2 7}$ & $\mathbf{- 3 . 8 6 4}(<\mathbf{0 . 0 0 1})$ \\
TL & $\mathbf{1 . 3 7 6} \pm \mathbf{0 . 2 1 8}$ & $\mathbf{6 . 3 0 4}(<\mathbf{0 . 0 0 1})$ \\
Body condition & $\mathbf{0 . 4 4 2} \pm \mathbf{0 . 1 1 4}$ & $\mathbf{3 . 8 8 4}(<\mathbf{0 . 0 0 1})$ \\
Predation risk & $\mathbf{- 9 . 4 0 2} \pm \mathbf{3 . 2 5 9}$ & $\mathbf{- 2 . 8 8 5}(\mathbf{0 . 0 0 4})$ \\
fGCM, ng/g & $\mathbf{- 0 . 0 1 3} \pm \mathbf{0 . 0 0 3}$ & $\mathbf{- 3 . 9 4 8}(<\mathbf{0 . 0 0 1})$ \\
Proportional nest cover & $\mathbf{- 2 . 0 2 3} \pm \mathbf{0 . 5 2 9}$ & $\mathbf{- 3 . 8 2 3}(<\mathbf{0 . 0 0 1})$ \\
Breeding experience $\times$ TL & $\mathbf{- 0 . 1 5 5} \pm \mathbf{0 . 0 5 0}$ & $\mathbf{- 3 . 0 4 9}(\mathbf{0 . 0 0 2})$ \\
Predation risk $\times$ fGCM & $\mathbf{0 . 0 5 7} \pm \mathbf{0 . 0 1 6}$ & $\mathbf{3 . 6 6 2}(<\mathbf{0 . 0 0 1})$ \\
Breeding experience $\times$ predation risk & $\mathbf{- 0 . 8 9 4} \pm \mathbf{0 . 3 7 8}$ & $\mathbf{- 2 . 3 6 7}(\mathbf{0 . 0 1 8})$ \\
Clutch size & $-0.0290 \pm 0.118$ & $\mathbf{- 0 . 2 4 4}(0.81)$ \\
TL $\times$ fGCM & $-0.001 \pm 0.002$ & $\mathbf{- 0 . 9 1 1}(0.362)$ \\
Body condition $\times$ fGCM & $-0.002 \pm 0.001$ & $\mathbf{- 1 . 4 5 3 ( 0 . 1 4 6 )}$ \\
TL $\times$ body condition & $0.252 \pm 0.241$ & $1.048(0.295)$ \\
Breeding experience $\times$ body condition & $0.0355 \pm 0.035$ & $1.021(0.307)$ \\
Breeding experience $\times$ fGCM & $0.000 \pm 0.0004$ & $0.701(0.483)$ \\
\hline
\end{tabular}

$f G C M$ faecal glucocorticoid metabolites, $S E$ standard error, $T L$ telomere length

$\mathrm{a}_{z}$ statistics and significance of the term $(\alpha=0.05)$ were obtained by comparing models with and without the given term a conservative model selection method that, despite being criticized, often performs similarly to alternative approaches (Murtaugh 2009).

The residuals of all models adhered to the assumption of independence and normality. We tested for multicollinearity by calculating the variance inflation factors (VIFs) for the independent variables in the two models. VIFs, calculated using the vif function in the car package in program $\mathrm{R}$, are defined as $1 /\left(1-r^{2}\right)$, where $r^{2}{ }_{j}$ is the coefficient of determination of the linear regression of regressor $j$ on the other regressors in the model. All variance inflation factors were below 1.13 , indicating that no multicollinearity was present, thus allowing the variables to be present in the same models.

Significant interaction terms between continuous variables were illustrated following Aiken and West (1991). Briefly, regression equations were restructured to reflect the regression of the criterion on one predictor and simple slope 
regressions were plotted to display the interaction at low (25\% quartile), intermediate (median) and high (75\% quartile) levels of the moderator variable. All other independent variables in the model are held constant, by centring them around their respective sample means. Although there is no consensus on how to estimate the effect size of interactions in mixed models, we reported the difference between the marginal coefficient of determination $\left(R^{2}\right)$ (i.e., the proportion of variance explained by the fixed effects alone) of the full model and the marginal $R^{2}$ of the model lacking the focal significant interaction term, as proposed by Nakagawa and Schielzeth (2013). In addition, we reported the total amount of variation accounted for by all the significant interactions together, to assess the relative importance of main effects versus interactions in explaining the variation in clutch size and hatching success, respectively. The marginal $R^{2}$ of models were calculated with the MuMIn package (Barton 2018).

\section{Results}

\section{Association between fGCM levels and predation}

There was a significant positive correlation between colony-specific predation risk and mean colony-specific logtransformed fGCM levels of females (Pearson correlation: $r=0.49, p=0.025, N=21$ ).

\section{Reproductive investment}

Colony-specific predation risk and fGCM interactively explained variation in clutch size (colony-specific predation $\times$ fGCM, $p<0.001$; Table 1 ). Thus, clutch size decreased with increasing fGCM levels when predation risk was high, but was nearly independent of fGCM levels when predation risk was low or intermediate (Fig. 1). The colonyspecific predation by fGCM interaction explained $4.2 \%$ of the total variance (marginal $R^{2}=0.197$ with interaction vs. marginal $R^{2}=0.155$ excluding the interaction). Similarly, female body condition and fGCM level had a significant interactive effect on clutch size (body condition $\times$ fGCM, $p=0.016$; Table 1). The clutch size of good-condition females decreased with increasing fGCM, whereas clutch size showed no obvious relationship with fGCM levels in intermediate and poor-condition females (Fig. 2). The body condition by fGCM interaction explained $4.2 \%$ of the total variance (marginal $R^{2}=0.197$ with interaction vs. marginal $R^{2}=0.155$ excluding the interaction). Female minimum breeding experience and telomere length, in an interactive manner, explained variation in clutch size (breeding experience $\times$ telomere length, $p=0.049$; Table 1). Younger females tended to show a slightly negative correlation between clutch size and telomere length whereas more experienced

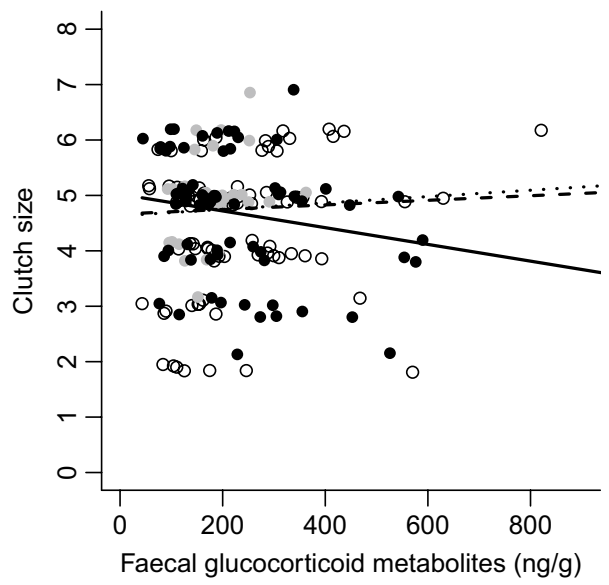

Fig. 1 Clutch size of female Eiders is related to their faecal glucocorticoid metabolite (fGCM) level and modulated by colony-specific predation risk (proportion of depredated nests). Under high predation risk (75 percentile, solid line, black dots), clutch size was negatively correlated with fGCM. A flat or slightly positive relationship was observed under low ( 25 percentile, dotted line, open circles) and intermediate (50 percentile, dashed line, grey dots) predation risk. The values for clutch size are jittered to make overlapping points visible. Note that this figure is for illustrative purposes, and that in our analyses we treated the variables included in the interaction term as continuous predictors

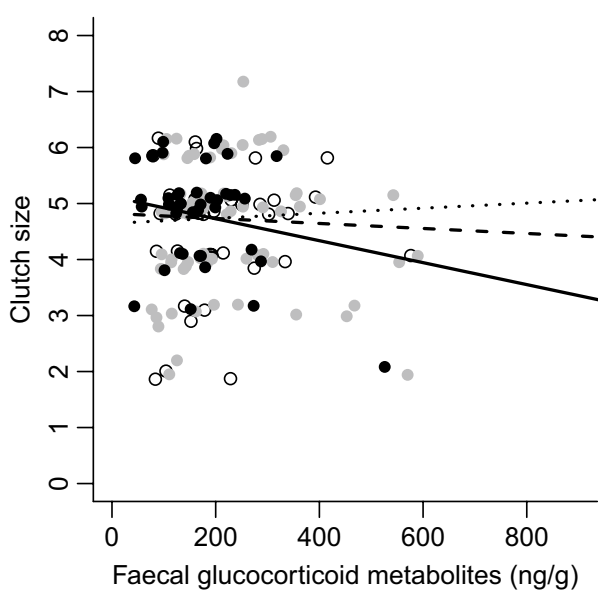

Fig. 2 Clutch size of female Eiders as a function of their faecal glucocorticoid metabolite (fGCM) level and body condition. Clutch size was negatively associated with fGCM for females in high body condition (75 percentile, solid line, black dots). No obvious relationship was observed for females in low condition ( 25 percentile, dotted line, open circles) or intermediate condition (50 percentile, dashed line, grey dots). The values for clutch size are jittered to make overlapping points visible. Note that this figure is for illustrative purposes, and that in our analyses we treated the variables included in the interaction term as continuous predictors

(i.e. older) females displayed a slightly positive correlation between clutch size and telomere length (Fig. 3). This third significant interaction explained $1.8 \%$ of the total variance 


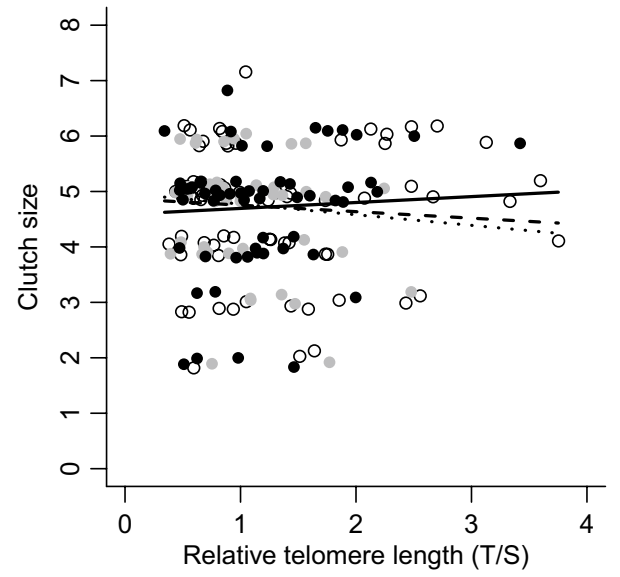

Fig. 3 The relationship between clutch size and relative telomere length of female Eiders is modulated by minimum years of maternal experience, a proxy for age. In young females (25 percentile, dotted line, open circles), increasing telomere length was associated with smaller clutches. In contrast, older females (75 percentile, solid line, black dots) laid slightly larger clutches with increasing telomere length. An intermediate relationship was observed for intermediateaged females ( 50 percentile, dashed line, grey dots). The values for clutch size are jittered to make overlapping points visible. Note that this figure is for illustrative purposes, and that in our analyses we treated the variables included in the interaction term as continuous predictors

(marginal $R^{2}=0.197$ with interaction vs. marginal $R^{2}=0.179$ excluding the interaction). Clutch size also increased with nest cover (Table 1). The three aforementioned significant interactions together accounted for $13 \%$ of the total variance in clutch size (marginal $R^{2}=0.197$ with interactions vs. marginal $R^{2}=0.0671$ excluding the interactions), a value to be compared with $6.7 \%$ of the variation explained by the fixed main effects alone.

\section{Hatching success}

Colony-specific predation risk and fGCM interactively explained variation in hatching success (colony-specific predation $\times \mathrm{fGCM}, p<0.001$; Table 2 ). This interaction revealed that the drop in hatching success with increasing fGCM levels was least pronounced under high nest predation risk (Fig. 4). The colony-specific predation by fGCM interaction explained $4.5 \%$ of the total variance (marginal $R^{2}=0.374$ with interaction vs. marginal $R^{2}=0.33$ excluding the interaction). Hatching success increased with female relative telomere length, but this increase was modulated by breeding experience (breeding experience $\times$ telomere length, $p=0.002$; Table 2). Older females generally showed higher hatching success than younger females, but the increase in hatching success with relative telomere length was accentuated for younger breeders (Fig. 5). This second interaction explained $0.8 \%$ of the total variance (marginal $R^{2}=0.374$

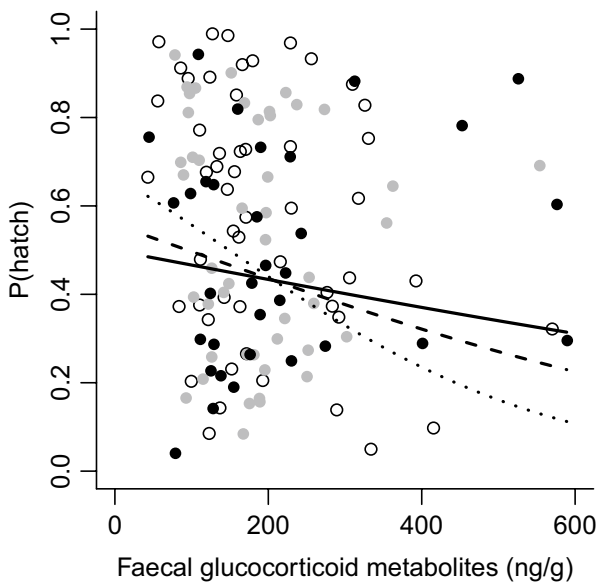

Fig. 4 Hatching success of female Eiders as a function of their faecal glucocorticoid metabolite (fGCM) level and colony-specific predation risk (proportion of depredated nests). Under high predation risk (75 percentile, solid line, black dots), the decrease in hatching success with increasing fGCM was the least pronounced. The corresponding decrease in hatching success was steepest when nest predation risk was low (25 percentile, dotted line, open circles), and of intermediate magnitude when predation risk was moderate (50 percentile, dashed line, grey dots). Note that this figure is for illustrative purposes, and that in our analyses we treated the variables included in the interaction term as continuous predictors

with interaction vs. marginal $R^{2}=0.366$ excluding the interaction). There was also a significant interaction between breeding experience and colony-specific predation risk (breeding experience $\times$ colony-specific predation, $p=0.018$;

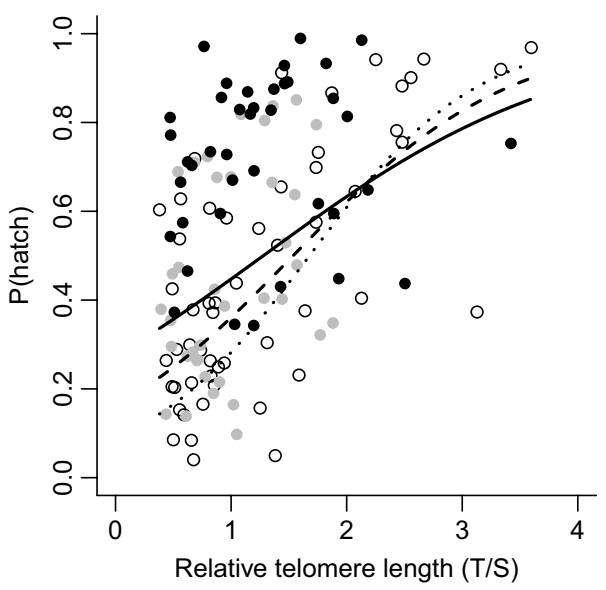

Fig. 5 Hatching success increased with relative telomere length of female Eiders, but this increase was modulated by minimum years of maternal experience, a proxy for age. The increase in hatching success with telomere length was most pronounced for young females ( 25 percentile, dotted line, open circles) compared to medium-aged (50 percentile, dashed line, grey dots) and older females ( 75 percentile, solid line, black dots). Note that this figure is for illustrative purposes, and that in our analyses we treated the variables included in the interaction term as continuous predictors 
Table 2). Hatching success increased with female breeding experience, but most markedly so under low predation risk (Fig. 6). The variance explained by this third interaction was $2.1 \%$ (marginal $R^{2}=0.374$ with interaction vs. marginal $R^{2}=0.353$ excluding the interaction). Hatching success also increased with maternal body condition, but decreased with later laying date and increasing nest cover (Table 2). The three significant interactions together accounted for $6.9 \%$ of the total variance in clutch size (marginal $R^{2}=0.374$ with interactions vs. marginal $R^{2}=0.305$ excluding the interactions), a value to be compared with $30.5 \%$ of the variation explained by the fixed main effects alone.

\section{Discussion}

Our results supported the expected positive relationship between predation risk and fGCM. Consistent with our first prediction of reduced CRI with increasing predation risk, clutch size decreased with increasing fGCM levels under high predation risk. Elevated perceived predation risk may promote physiological changes that aid survival but reduce investment in egg production (Bonier et al. 2009a; Clinchy et al. 2011; Zanette et al. 2011). In contrast, females breeding in areas with lower predation risk showed, if anything, a weak positive association between clutch size and maternal fGCM levels (Fig. 1). Particularly pertinent is the variation in fGCM levels under high and low threat from predators. Female fGCM levels under high predation risk were

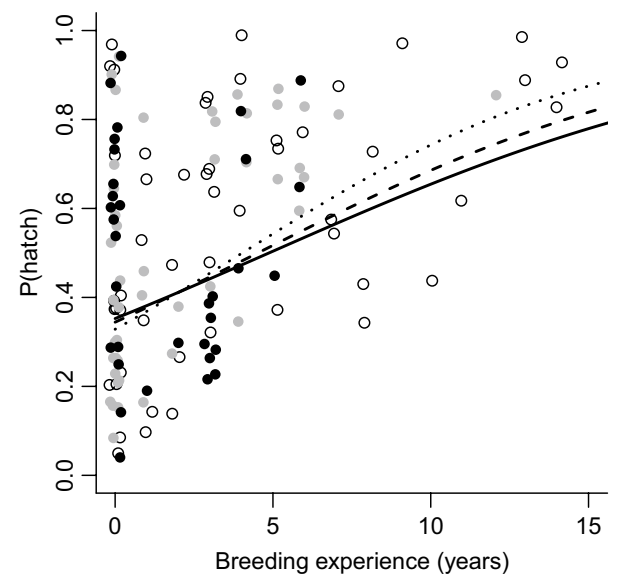

Fig. 6 Hatching success increased with minimum years of maternal experience of female Eiders, but this increase was modulated by colony-specific predation risk. The increase in hatching success with breeding experience was most pronounced under low predation risk (25 percentile, dotted line, open circles), least pronounced under high risk (75 percentile, solid line, black dots) and of intermediate magnitude in colonies having an intermediate risk (50 percentile, dashed line, grey dots). Note that this figure is for illustrative purposes, and that in our analyses we treated the variables included in the interaction term as continuous predictors numerically, although not statistically significantly, higher $(238.9 \pm 138.3(\mathrm{SD}) \mathrm{ng} / \mathrm{g})$ than under low predation risk $(196.3 \pm 92.1 \mathrm{ng} / \mathrm{g})\left(t_{78.71}=-1.73, p=0.088\right)$. Thus, moderately elevated fGCMs, potentially characterizing females nesting in safer colonies, may be associated with increased reproductive allocation, e.g. through more efficient acquisition of food resources for egg production ('cort-adaptation hypothesis'; Bonier et al. 2009a; Crossin et al. 2012; Love et al. 2014). Potentially, the apparent decline in clutch size under high predation risk in females with high fGCM levels may be an artefact of undetected partial clutch predation that is particularly common during early laying, when nest attendance is low (Öst et al. 2008). However, this possibility seems unlikely for two reasons. First, the proportion of successfully hatched offspring decreased less with increasing fGCM in more risky areas (Fig. 4). Second, well-covered nests had lower proportional hatching success (Table 2), whereas (early) partial clutch predation is expected to be lower in such nests (Öst et al. 2008).

It is important to recognize that clutch size is but one measure of reproductive investment. In Eiders, egg mass is closely positively correlated with duckling body condition (Öst et al. 2020). Considering the potential trade-off between clutch size and egg mass (Stearns 1992), the question arises as to whether the observed changes in clutch size may be mitigated by compensatory changes in egg mass. However, this possibility is unlikely in the present study. Thus, there is no correlation between clutch size and mean egg mass per clutch $(r=-0.094, p=0.19, N=190)$, standardized for incubation stage according to Öst et al. (2020). Thus, from a cross-sectional perspective, female Eiders producing larger clutches appear able to do so without compromising offspring quality.

In line with our second prediction that individuals with high RRV should reduce CRI to ensure future reproductive opportunities, females in good body condition produced smaller clutches with increasing fGCM levels (Fig. 2). Females in good body condition are likely to have high RRV, as evidenced by their higher survival (Ekroos et al. 2012), nest success (Lehikoinen et al. 2010) and post-hatching duckling survival (Bustnes and Erikstad 1991) than females in poor body condition. Higher RRV is expected to make animals risk averse when confronted with environmental challenges or reproductive stress (Clark 1994; Wolf et al. 2007), in this case, reflected in elevated fGCMs. Producing a smaller clutch may reduce metabolic demands and the time spent laying and incubating eggs, so minimizing exposure to predators (Martin 2002). One possible mechanism may relate to condition-dependent resource allocation to reproduction. Thus, female Eiders in good body condition breed earlier (Jaatinen and Öst 2016; Laursen et al. 2019), and more extensively utilize stored reserves for producing their eggs (Jaatinen et al. 2016). A corollary is that it may 
be optimal for females in good body condition to promptly initiate breeding after arrival, so as not to deplete stored energy reserves. In contrast, females in poor condition may maximize their reproductive output by intense foraging after arrival, which delays breeding. Such intense feeding activity may be facilitated by increased corticosterone levels (Crossin et al. 2012). Indeed, late-nesting females show a pronounced increase in baseline plasma corticosterone levels with increased reproductive effort (indexed by total clutch mass) (Jaatinen et al. 2013). Differential breeding resource allocation strategies may, therefore, potentially explain the differential relationship between clutch size and fGCM levels (Fig. 2) when comparing females in good and poor body condition, respectively.

Reproductive effort has been shown to cause telomere attrition in mammals (e.g., Kotrschal et al. 2007) and birds (e.g., Heidinger et al. 2012). We showed that younger females with longer telomeres tended to produce smaller clutches (Fig. 3), although we advise caution in interpreting this result given the low effect size of the interaction between breeding experience and telomere length. It is plausible that such females have high RRV, providing an incentive for them not to put excessive effort into their current reproduction which may shorten their telomeres and reduce their future reproductive prospects (Kotrschal et al. 2007). The clutch sizes of older females, on the other hand, were weakly positively correlated with telomere length (Fig. 3). Telomere length may predict remaining lifespan (Heidinger et al. 2012), and reproductive capacity tends to increase with age (Figs. 5, 6; Clutton-Brock 1988). If so, a positive correlation between lifespan, potentially associated with longer telomeres, and reproductive performance may be expected in older, more experienced females. It is noteworthy that the relative telomere length of adult female eiders shows no significant trend with age (Noreikiene et al. 2017). However, because both this study and our current findings are based on cross-sectional observational data, longitudinal data on telomere length will now be needed to infer any causal connections between telomere length, breeding experience and fitness.

We observed a negative association between fGCM and hatching success (Fig. 4) in support of the corticosteronefitness hypothesis (Bonier et al. 2009a). However, we find that females in high predation areas sustained relatively better performance with increasing fGCM, concomitant with a reduction in clutch size (Fig. 1). Hence, reduced clutch size in response to increased predation risk may ultimately provide a relative reproductive advantage, consistent with our third prediction. The higher hatching success of these females' clutches was not a by-product of clutch sizedependent hatching success (Table 2).

Increased glucocorticoid reactivity upon immediate threat (plasma CORT: Jaatinen et al. 2014) or during prolonged exposure (fGCM; this study) may confer benefits under predation risk by preparing individuals for potential threats (Romero 2002). One possible mechanism is through a more efficient escape from predation. Thus, higher handlinginduced plasma corticosterone reactivity is associated with an earlier escape response from the nest (Seltmann et al. 2012). Female eiders may successfully hatch a clutch after managing to escape a predator attack (pers. obs. using wildlife cameras), indicating a potential association between increased glucocorticoid reactivity and hatching success, mediated through more efficient avoidance of being captured once attacked. Second, higher handling-induced glucocorticoid levels are associated with a shorter incubation period (Seltmann et al. 2012), which should reduce exposure time to predators. To conclude, females with elevated maternal fGCM levels may suffer a relatively smaller loss of reproductive success in areas of high nest predation risk, where predation on adult females is also intense (Öst et al. 2018).

Our results indicate the utility of telomere length and age as indicators of individual quality: hatching success increased with maternal telomere length (Fig. 5) and years of breeding experience (Figs. 5, 6). Likewise, telomere length is correlated with individual quality in other longlived birds (Pauliny et al. 2006; Vaillant et al. 2015; Angelier et al. 2019), and breeding experience is a key determinant of avian breeding performance (e.g., Forslund and Pärt 1995). A potential mechanism for age-related improvements in breeding competence may involve the pituitary hormone prolactin. Prolactin is essential for regulating parental care and older parents are typically more adept at maintaining adequate levels of this hormone (Angelier et al. 2007). Alternatively, the observed age-associated improvement in reproductive performance may reflect selective disappearance (Curio 1983). Longitudinal studies would be needed to separate within-individual (individual improvement) from between-individual (selective disappearance) effects of age on reproductive performance.

To conclude, increased predation risk was coupled with elevated fGCM levels of breeding females. We further showed that high potential for future breeding prospects and increased predation risk may restrain current reproductive investment, with glucocorticoids playing a role in the resolution of this trade-off. Thus, elevated fGCM levels were negatively correlated with CRI under high predation threat and for females in good body condition. Furthermore, elevated maternal glucocorticoid levels may serve as a buffer against the loss of reproductive success under severe predation pressure. Lastly, we showed that body condition, telomere length and breeding experience (age) can serve as phenotypic quality indicators in Eiders, the latter two having interactive effects on CRI and hatching success. However, two final cautionary notes are in order. First, it should be noted that the interactive effects involving hatching success 
were generally relatively weak compared to those involving clutch size. Second, because our correlational data preclude causal interpretation, the intricate relationships indicated by our study await further elucidation by longitudinal and experimental work involving not only predation but also competition and food limitation.

Acknowledgements We thank Martin Seltmann for performing the fGCM analyses. We are grateful to Pat Monaghan and Winnie Boner for helpful discussions. Tvärminne Zoological Station provided excellent working facilities. The capture and handling of birds comply with the current laws of Finland.

Funding Open access funding provided by Abo Akademi University (ABO). The authors were supported by Academy of Finland (grant numbers: 128039 (MÖ), 266208 (KJ) and 1265211 to Juha Merilä which supported work of KN), Finnish Cultural Foundation (KN and $\mathrm{KJ})$, Societas pro Fauna et Flora Fennica (KN), Otto A. Malm foundation $(\mathrm{KN})$, Oskar Öflund foundation (KN), the Swedish Cultural Foundation in Finland (MÖ), Nordenskiöld-samfundet (KN), LUOVA Doctoral Programme in Wildlife Biology $(\mathrm{KN})$, European Regional Development Fund and the programme Mobilitas Pluss (Grant No MOBJD344), and the Faculty Development Fund of Colby-Sawyer College (BBS).

Data availability Data is available as an associated file deposited on ResearchGate.

\section{Compliance with ethical standards}

Conflict of interest The authors declare that they have no conflict of interests.

Ethical approval Eider handling procedures were approved by the Animal Experiment Board/State Provincial Office of Southern Finland (permit number ESLH-2009-02969/Ym-23) and followed regulations set by the Tvärminne Zoological Station.

Open Access This article is licensed under a Creative Commons Attribution 4.0 International License, which permits use, sharing, adaptation, distribution and reproduction in any medium or format, as long as you give appropriate credit to the original author(s) and the source, provide a link to the Creative Commons licence, and indicate if changes were made. The images or other third party material in this article are included in the article's Creative Commons licence, unless indicated otherwise in a credit line to the material. If material is not included in the article's Creative Commons licence and your intended use is not permitted by statutory regulation or exceeds the permitted use, you will need to obtain permission directly from the copyright holder. To view a copy of this licence, visit http://creativecommons.org/licenses/by/4.0/.

\section{References}

Aiken LS, West SG (1991) Multiple regression: testing and interpreting interactions. Sage, Thousand Oaks

Andersson M, Waldeck P (2006) Reproductive tactics under severe egg predation: an Eiders' dilemma. Oecologia 148:350-355
Angelier F, Moe B, Weimerskirch H, Chastel O (2007) Age-specific reproductive success in a long-lived bird: do older parents resist stress better? J Anim Ecol 76:1181-1191

Angelier F, Weimerskirch H, Barbraud C, Chastel O (2019) Is telomere length a molecular marker of individual quality? Insights from a long-lived bird. Funct Ecol 33:1076-1087

Barton K (2018) Package 'MuMIn'. https://cran.r-project.org/web/ packages/MuMIn/MuMIn:18. Accessed 27 Oct 2020

Bauch C, Becker PH, Verhulst S (2013) Telomere length reflects phenotypic quality and costs of reproduction in a long-lived seabird. Proc Biol Sci 280:20122540

Beaulieu M, Reichert S, Le Maho Y, Ancel A, Criscuolo F (2011) Oxidative status and telomere length in a long-lived bird facing a costly reproductive event. Funct Ecol 25:577-585

Bokony V, Lendvai AZ, Liker A, Angelier F, Wingfield JC, Chastel O (2009) Stress response and the value of reproduction: are birds prudent parents? Am Nat 173:589-598

Bolduc F, Guillemette M (2003) Human disturbance and nesting success of Common Eiders: interaction between visitors and gulls. Biol Conserv 110:77-83

Bonier F, Martin PR, Moore IT, Wingfield JC (2009a) Do baseline glucocorticoids predict fitness? Trends Ecol Evol 24:634-642

Bonier F, Moore IT, Martin PR, Robertson RJ (2009b) The relationship between fitness and baseline glucocorticoids in a passerine bird. Gen Comp Endocrinol 163:208-213

Bustnes JO, Erikstad KE (1991) Parental care in the Common Eider (Somateria mollissima): factors affecting abandonment and adoption of young. Can J Zool 69:1538-1545

Cawthon RM (2002) Telomere measurement by quantitative PCR. Nucleic Acids Res 30:e47

Cerchiara JA, Risques RA, Prunkard D, Smith JR, Kane OJ, Boersma PD (2017) Magellanic Penguin telomeres do not shorten with age with increased reproductive effort, investment, and basal corticosterone. Ecol Evol 7:5682-5691

Clark CW (1994) Antipredator behavior and the asset-protection principle. Behav Ecol 5:159-170

Clinchy M, Zanette L, Charlier TD, Newman AEM, Schmidt KL, Boonstra R, Soma KK (2011) Multiple measures elucidate glucocorticoid responses to environmental variation in predation threat. Oecologia 166:607-614

Clutton-Brock TH (1988) Reproductive success. In: Clutton-Brock TH (ed) Reproductive success: studies of individual variation in contrasting breeding systems. University of Chicago Press, Chicago, pp 472-485

Cockrem JF, Silverin B (2002) Sight of a predator can stimulate a corticosterone response in the Great Tit (Parus major). Gen Comp Endocrinol 125:248-255

Criscuolo F, Bize P, Nasir L, Metcalfe NB, Foote CG, Griffiths K, Gault EA, Monaghan P (2009) Real-time quantitative PCR assay for measurement of avian telomeres. J Avian Biol 40:342-347

Crossin GT, Trathan PN, Phillips RA, Gorman KB, Dawson A, Sakamoto KQ, Williams TD (2012) Corticosterone predicts foraging behavior and parental care in Macaroni Penguins. Am Nat 180:E31-E41

Curio E (1983) Why do young birds reproduce less well? Ibis 125:400-404

D’Alba L, Spencer KA, Nager RG, Monaghan P (2011) State-dependent effects of elevated hormone: nest site quality, corticosterone levels and reproductive performance in thecommon eider. Gen Comp Endocrinol 172:218-224

Ekroos J, Öst M, Karell P, Jaatinen K, Kilpi M (2012) Philopatric predisposition to predation-induced ecological traps: habitatdependent mortality of breeding Eiders. Oecologia 170:979-986

Forslund P, Pärt T (1995) Age and reproduction in birds-hypotheses and tests. Trends Ecol Evol 10:374-378 
Ghalambor CK, Martin TE (2000) Parental investment strategies in two species of nuthatch vary with stage-specific predation risk and reproductive effort. Anim Behav 60:263-267

Hanssen SA, Hasselquist D, Folstad I, Erikstad KE (2005) Cost of reproduction in a long-lived bird: incubation effort reduces immune function and future reproduction. Proc Biol Sci 272:1039-1046

Hario M, Rintala J (2009) Age of first breeding in the Common Eider Somateria m. mollissima population in the northern Baltic Sea. Ornis Fenn 86:81-88

Hau M, Haussmann MF, Greives TJ, Matlack C, Costantini D, Quetting M, Adelman JS, Miranda AC, Partecke J (2015) Repeated stressors in adulthood increase the rate of biological ageing. Front Zool 12:4

Heidinger BJ, Blount JD, Boner W, Griffiths K, Metcalfe NB, Monaghan P (2012) Telomere length in early life predicts lifespan. Proc Natl Acad Sci USA 109:1743-1748

Hellman J (2017) Haahkanaaraan (Somateria mollissima) pitkäaikaisen paaston fysiologiset vaikutukset. MSc thesis, University of Helsinki

Hobson KA, Jaatinen K, Öst M (2015) Differential contributions of endogenous and exogenous nutrients to egg components in wild Baltic Common Eiders (Somateria mollissima): a test of alternative stable isotope approaches. Auk 132:624-633

Ibáñez-Álamo JD, Chastel O, Soler M (2011) Hormonal response of nestlings to predator calls. Gen Comp Endocrinol 171:232-236

Jaatinen K, Öst M (2011) Experience attracts: the role of age in the formation of cooperative brood-rearing coalitions in Eiders. Anim Behav 81:1289-1294

Jaatinen K, Öst M (2016) Brain size-related breeding strategies in a seabird. Oecologia 180:67-76

Jaatinen K, Seltmann MW, Hollmén T, Atkinson S, Mashburn K, Öst M (2013) Context dependency of baseline glucocorticoids as indicators of individual quality in a capital breeder. Gen Comp Endocrinol 191:231-238

Jaatinen K, Seltmann MW, Öst M (2014) Context-dependent stress responses and their connections to fitness in a landscape of fear. J Zool 294:147-153

Jaatinen K, Öst M, Hobson KA (2016) State-dependent capital and income breeding: a novel approach to evaluating individual strategies with stable isotopes. Front Zool 13:24

Jimeno B, Hau M, Verhulst S (2018) Corticosterone levels reflect variation in metabolic rate, independent of 'stress.' Sci Rep 8:1-8

Kilpi M, Lindström K (1997) Habitat-specific clutch size and cost of incubation in Common Eiders, Somateria mollissima. Oecologia 111:297-301

Kotrschal A, Ilmonen P, Penn DJ (2007) Stress impacts telomere dynamics. Biol Lett 3:128-130

Laursen K, Møller AP, Öst M (2019) Body condition of Eiders at Danish wintering grounds and at pre-breeding grounds in Åland. J Ornithol 160:239-248

Legagneux P, Gauthier G, Chastel O, Picard G, Bêty J (2011) Do glucocorticoids in droppings reflect baseline level in birds captured in the wild? A case study in Snow Geese. Gen Comp Endocrinol 172:440-445

Lehikoinen A, Kilpi M, Öst M (2006) Winter climate affects subsequent breeding success of Common Eiders. Glob Change Biol 12:1355-1365

Lehikoinen A, Jaatinen K, Öst M (2010) Do female ornaments indicate quality in Eider ducks? Biol Lett 6:225-228

Love OP, Madliger CL, Bourgeon S, Semeniuk CAD, Williams TD (2014) Evidence for baseline glucocorticoids as mediators of reproductive investment in a wild bird. Gen Comp Endocrinol 199:65-69
Martin TE (2002) A new view of avian life-history evolution tested on an incubation paradox. Proc Biol Sci 269:309-316

Mizutani Y, Tomita N, Niizuma Y, Yoda K (2013) Environmental perturbations influence telomere dynamics in long-lived birds in their natural habitat. Biol Lett 9:20130511

Monaghan P (2014) Organismal stress, telomeres and life histories. J Exp Biol 217:57-66

Murtaugh PA (2009) Performance of several variable-selection methods applied to real ecological data. Ecol Lett 12:1061-1068

Nakagawa S, Schielzeth H (2013) A general and simple method for obtaining $R^{2}$ from generalized linear mixed-effects models. Methods Ecol Evol 4:133-142

Neggazi SA, Noreikiene K, Öst M, Jaatinen K (2016) Reproductive investment is connected to innate immunity in a long-lived animal. Oecologia 182:347-356

Nilsson PB, Hollmén TE, Atkinson S, Mashburn KL, Tuomi PA, Esler D, Mulcahy DM, Rizzolo DJ (2008) Effects of ACTH, capture, and short term confinement on glucocorticoid concentrations in Harlequin Ducks (Histrionicus histrionicus). Comp Biochem Physiol A Mol Integr Physiol 149:275-283

Noreikiene K, Öst M, Seltmann MW, Boner W, Monaghan P, Jaatinen K (2017) Nest cover and faecal glucocorticoid metabolites are linked to hatching success and telomere length in breeding Common Eiders (Somateria mollissima). Can J Zool 95:695-703

Öst M, Steele BB (2010) Age-specific nest-site preference and success in Eiders. Oecologia 162:59-69

Öst M, Wickman M, Matulionis E, Steele BB (2008) Habitat-specific clutch size and cost of incubation in Eiders reconsidered. Oecologia 158:205-216

Öst M, Lehikoinen A, Jaatinen K, Kilpi M (2011) Causes and consequences of fine-scale breeding dispersal in a female-philopatric species. Oecologia 166:327-336

Öst M, Lindén A, Karell P, Ramula S, Kilpi M (2018) To breed or not to breed: drivers of intermittent breeding in a seabird under increasing predation risk and male bias. Oecologia 188:129-138

Öst M, Noreikiene K, Angelier F, Jaatinen K (2020) Sex-specific effects of the in ovo environment on early-life phenotypes in Eiders. Oecologia 192:43-54

Pauliny A, Wagner RH, Augustin J, Szép T, Blomqvist D (2006) Ageindependent telomere length predicts fitness in two bird species. Mol Ecol 15:1681-1687

Plot V, Criscuolo F, Zahn S, Georges JY (2012) Telomeres, age and reproduction in a long-lived reptile. PLoS ONE 7:e40855

R Core Team (2017) R: a language and environment for statistical computing. R Foundation for Statistical Computing, Vienna, Austria. https://www.R-project.org/

Romero LM (2002) Seasonal changes in plasma glucocorticoid concentrations in free-living vertebrates. Gen Comp Endocrinol 128:1-24

Seltmann MW, Öst M, Jaatinen K, Atkinson S, Mashburn K, Hollmén T (2012) Stress responsiveness, age and body condition interactively affect flight initiation distance in breeding female Eiders. Anim Behav 84:889-896

Seltmann MW, Jaatinen K, Steele BB, Öst M (2014) Boldness and stress responsiveness as drivers of nest-site selection in a groundnesting bird. Ethology 120:77-89

Stearns SC (1992) The evolution of life histories. Oxford University Press, New York

Sudyka J, Arct A, Drobniak S et al (2014) Experimentally increased reproductive effort alters telomere length in the blue tit (Cyanistes caeruleus). J Evol Biol 27:2258-2264

Thierry AM, Massemin S, Handrich Y, Raclot T (2013) Elevated corticosterone levels and severe weather conditions decrease parental investment of incubating Adélie Penguins. Horm Behav $63: 475-483$ 
Vaillant ML, Viblanc VA, Saraux C, Bohec CL, Maho YL, Kato A, Criscuolo F, Ropert-Coudert Y (2015) Telomere length reflects individual quality in free-living adult King Penguins. Polar Biol 38:2059-2067

Vaziri H, Dragowska W, Allsopp RC, Thomas TE, Harley CB, Lansdorp PM (1994) Evidence for a mitotic clock in human hematopoietic stem cells: loss of telomeric DNA with age. Proc Natl Acad Sci USA 91:9857-9860

Velando A, Drummond H, Torres R (2006) Senescent birds redouble reproductive effort when ill: confirmation of the terminal investment hypothesis. Proc Biol Sci 273:1443-1448

Waldeck P, Kilpi M, Öst M, Andersson M (2004) Brood parasitism in a population of Common Eider (Somateria mollissima). Behaviour 141:725-739

Waldeck P, Andersson M, Kilpi M, Öst M (2008) Spatial relatedness and brood parasitism in a female-philopatric bird population. Behav Ecol 19:67-73

Williams GC (1966) Natural selection, the costs of reproduction, and a refinement of Lack's principle. Am Nat 100:687-690
Wingfield JC, Maney DL, Breuner CW, Jacobs JD, Lynn S, Ramenofsky M, Richardson RD (1998) Ecological bases of hormonebehavior interactions: the "emergency life history stage." Am Zool 38:191-206

Wolf M, van Doorn GS, Leimar O, Weissing FJ (2007) Life-history trade-offs favour the evolution of animal personalities. Nature 447:581-584

Zanette LY, White AF, Allen MC, Clinchy M (2011) Perceived predation risk reduces the number of offspring songbirds produce per year. Science 334:1398-1401

Publisher's Note Springer Nature remains neutral with regard to jurisdictional claims in published maps and institutional affiliations. 